\title{
STRATEGI PENGEMBANGAN UKM DIGITAL DALAM MENGHADAPI ERA PASAR BEBAS
}

\section{DEVELOPMENT STRATEGY OF DIGITAL START UP TO CONFRONT THE ERA OF FREE MARKET}

\author{
Rachmat Slamet ${ }^{1}$, Bilpen Nainggolan ${ }^{2}$, Roessobiyatno ${ }^{3}$, Heru Ramdani ${ }^{4}$, Agung \\ Hendriyanto $^{5}$, Luk lu'ul Ilma ${ }^{6}$ \\ Researcher, PT. Telekomunikasi Indonesia, Tbk. Divisi Digital Service \\ ${ }^{1}$ rachmatslamet@telkom.co.id, ${ }^{2}$ bil@telkom.co.id, ${ }^{3}$ roesso@telkom.co.id, \\ ${ }^{4}$ hera@telkom.co.id, ${ }^{5}$ goeng@telkom.co.id, ${ }^{6}$ luk@telkom.co.id
}

JURNAL

MANAJEMEN

INDONESIA

Vol.16 - No.2

APRIL 2016

\begin{abstract}
Abstrak
Penelitian ini bertujuan untuk mengembangkan Usaha Kecil dan Menengah secara digital sebagai strategi dalam menghadapi era Pasar Bebas. Penelitian ini dilakukan berdasarkan desk research and indepth interview terhadap 70 UKM Kampung UKM Digital Skoci (Bandung) dan Trusmi (Cirebon). Data yang dikumpulkan dianalisis menggunakan metode kualitatif dan teknik analisis data SWOT untuk merumuskan strategi dan program jangka pendek, menengah, dan panjang. Hasil yang diperoleh dalam penelitian ini menunjukkan bahwa diperlukannya strategi pengembangan secara digital terhadap UKM dalam penyediaan infrastruktur ICT, proses produksi, dan perluasan pasar baik dalam jangka pendek, jangka menengah, dan jangka panjang agar para UKM memiliki daya saing dan meningkatkan kinerjanya.
\end{abstract}

Kata kunci : strategi, UKM, digital, daya saing, kinerja, dan ICT

\section{Abstract}

This research aims to digitally develop Small and Medium Business as a strategy to face the Era of Free Market. This research was conducted by using desk research and in-depth interviews with 70 SME Kampung SME Digital Skoci (Bandung) and Trusmi (Cirebon). The data collected were analyzed by using qualitative methods and SWOT techniques of data analysis to formulate short-term, medium and long term strategies and programs. The results obtained in this study shown that the strategy to digitally develop SMEs is required in the provision of ICT infrastructure, production process, and market expansion for both short term, medium term and long term for SMEs to obtain competitiveness and increased performance.

Keywords: strategy, SMEs, digital, competitiveness, performance, and ICT

\section{Pendahuluan}

Dengan diberlakukannya MEA pada tahun 2015, negara anggota ASEAN akan mengalami aliran bebas barang, jasa, investasi, dan tenaga kerja terdidik dari dan ke masing-masing negara. Bagaimana Indonesia sebagai bagian dari komunitas ASEAN berusaha untuk mempersiapkan dan memanfaatkan peluang MEA, serta harus meningkatkan kapabilitas untuk dapat bersaing dengan negara anggota ASEAN lainnya. Sejauh ini, langkah-langkah yang telah dilakukan oleh Indonesia berdasarkan rencana strategis pemerintah untuk menghadapi MEA/AEC, antara lain Penguatan Sektor UKM (eJournal Ilmu Hubungan Internasional, 2013).

Pemerintah telah berupaya meningkatkan akses dan transfer teknologi untuk mengembangkan pelaku UKM inovatif yang antara lain dengan pemanfaatan teknologi informasi dan komunikasi (TIK) sehingga diharapkan akan mampu bersaing dengan pelaku UKM asing. Saat ini, pemasaran produk dan pelayanan perusahaan merupakan proses yang interaktif akibat penggunaan teknologi informasi. Perusahaan tidak hanya menyediakan katalog produk dan promosi di situs-nya, namun situs perusahaan sudah digunakan sebagai sarana untuk berdialog, berdiskusi, dan berkonsultasi dengan konsumen secara online, menampilkan buletin boards, membuat kuesioner elektronik, mailing list, dan koordinasi melalui surat elektronik (Rustono, 2013). 


\section{JURNAL}

MANAJEMEN

INDONESIA

Vol.16 - No.2

APRIL 2016

Pelaku bisnis di Indonesia semakin menyadari kekuatan internet dan perangkat digital dalam peningkatan kinerja usahanya (Deloitte, 2015). Situs, media sosial, dan aplikasi mobile messaging merupakan media yang sangat penting bagi pelaku UKM dalam berinteraksi dengan konsumen (Deloitte, 2015). Sebanyak 38\% pemilik dan manager bisnis menyatakan bahwa situs merupakan hal yang sangat penting bagi mereka untuk berinteraksi dengan konsumen, sedangkan 32\% dan 23\% memilih media sosial dan aplikasi mobile messaging dalam berinteraksi dengan konsumen. Lebih lanjut Delloite menyampaikan hasil risetnya terhadap 437 UKM yang tersebar di kota Medan, Jakarta, Bandung, Semarang, Surabaya dan Makasar yang menunjukan beberapa keuntungan penggunaan teknologi digital bagi UKM di Indonesia adalah: kenaikan pendapatan hingga $80 \%$, satu setengah kali lebih mungkin untuk meningkatkan kesempatan kerja, 17 kali lebih mungkin untuk menjadi lebih inovatif dan UKM lebih kompetitif secara internasional (Delloite, 2015).

Demikian pula hasil riset kami di tahun 2016 terhadap 60 UKM yang berlokasi di Sentra Industri SKOCI Bandung dan Batik Trusmi Cirebon bahwa digitalisasi memberikan pengaruh terhadap peningkatan kinerja UKM berupa: Akses ke pelanggan baru di Dalam Negeri 30,67\%, Peningkatan penjualan dan pendapatan 26,67\%, Kemudahan transaksi dengan pelanggan dan pemasok 20,33\%, Biaya periklanan yang lebih murah $14,78 \%$ dan Akses market baru di Luar Negeri 7,56\%.

Indonesia merupakan negara yang memiliki pelaku industri UKM paling banyak, hal ini disebabkan oleh tingginya usia produktif di Indonesia yang tidak berbanding lurus dengan ketersediaan jumlah lapangan pekerjaan (menurut Ketua Dewan Pertimbangan Kadin DKI, Dhaniswara K Harjono) (merdeka.com, 2014), mendorong orang Indonesia berlomba-lomba menciptakan terobosan untuk meningkatkan daya saing demi memajukan perekonomian masing-masing. Tidak heran semakin banyak bermunculan pelaku usaha sektor industri Usaha Kecil Menengah. Pemberdayaan usaha mikro, kecil dan menengah (UMKM) di berbagai daerah akan menjadi solusi jitu guna mengatasi kelesuan yang sedang melanda kondisi perekonomian nasional saat ini. Hal tersebut menunjukkan bahwa UKM atau UMKM memiliki pengaruh yang besar terhadap perekonomian Indonesia.

Dalam rancangan kebijakan Masterplan Percepatan dan Perluasan Pembangunan Ekonomi Indonesia (MP3EI), Pemerintah Indonesia berkomitmen untuk mengubah Indonesia menjadi negara berpendapatan menengah pada tahun 2025 . Untuk mencapai hal tersebut Indonesia membutuhkan setidaknya pertumbuhan ekonomi $7 \%$ per tahun, $2 \%$ diatas rata-rata pertumbuhan ekonomi selama ini.

Dapat menjadi pelajaran bagi kita bahwa pada saat krisis ekonomi melanda di Indonesia tahun 1997 lalu, dimana banyak perusahaan-perusahaan besar yang mengalami kerugian, kelesuan dan bahkan berhenti aktifitas usahanya. Namun Usaha Kecil dan Menengah terbutki lebih tangguh dalam menghadapi krisis ekonomi tersebut dan mampu menyelamatkan perekonomian Indonesia pada saat dilanda kiris, sehingga sektor Usaha Kecil dan Menengah sangat diharapkan untuk mampu meningkatkan pertumbuhan ekonomi.

Menurut data dari Asian Development Bank (ADB) Institute tahun 2015, Indonesia merupakan negara yang memiliki kontribusi terbanyak dari SME / UKM terhadap PDB $57,8 \%$, penyerapan tenaga kerja $97,2 \%$, serta total ekspor $15,8 \%$ sebagaimana terlihat pada Gambar-1.

Gambar 1.

SME Share Of

Employment, Export And Contribution To GDP)
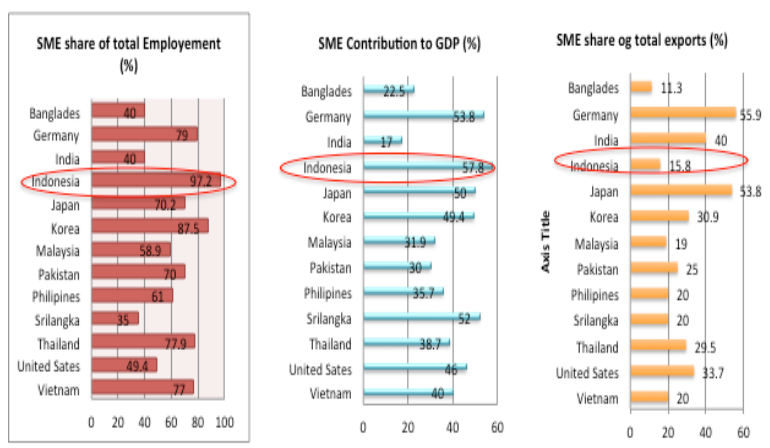
Dengan 57 juta lebih UKM yang ada di Indonesia, tentu akan memberikan dampak yang signifikan terhadap pertumbuhan ekonomi di Indonesia.

Berbagai program telah dilaksanakan oleh Pemerintah untuk memajukan dan mendorong UKM dan terbukti dari hasil survey Asean SME Policy Index 2014, " Asean SME Policy Index, 2014,” 2014) Indonesia memiliki indeks sebesar 4.1. Hal ini menunjukkan bahwa pemerintah Indonesia memiliki kinerja cukup baik dibandingkan dengan negara-negera lain dalam menerapkan berbagai kebijakan tentang pengembangan UKM. seperti terlihat pada Gambar-2

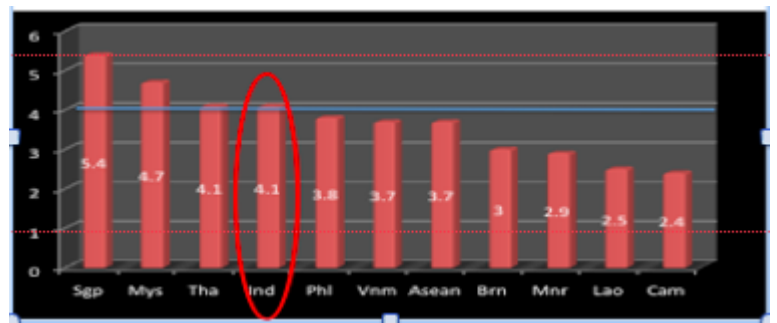

Sejalan dengan program pemerintah dalam memajukan UKM, PT. TELKOM kini sedang menggalakan program Pembangunan Kampung UKM Digital. Yaitu kampung dimana pemanfaatan teknologi informasi secara komprehensif dan integratif untuk mendukung proses bisnis yang berjalan di Sentra UKM atau UKM yang terpusat di suatu lokasi tertentu dalam rangka mewujudkan jutaan UKM yang maju, mandiri, dan modern.

Inisiasi kampung UKM Digital merupakan wujud bakti Telkom untuk membantu UKM Indonesia dalam rangka meningkatkan pertumbuhan ekonomi Indonesia, modernisasi dan peningkatan kompetensi serta daya saing UKM melalui ICT.

Implementasi dari Kampung UKM Digital ini ditandai dengan beberapa parameter diantaranya:

1) Tersedianya jaringan infrastruktur telekomunikasi baik berupa jaringan fixed, wirelles maupun satelit yang menjangkau seluruh wilayah kampung UKM.

2) Adanya wadah komunitas/ Tenaga Wira IT dan sarana pelatihan berupa Broadband Learning Center.

3) Dilakukan pemanfaatan solusi dan layanan Teknologi Infomasi di dalam lingkungan Kampung UKM.

Ratusan Kampung UKM Digital dibeberapa kota di Indonesia telah diresmikan, namun dalam pengelolaannya selama ini masih dijumpai beberapa kendala sehingga diperlukan strategi untuk pengembangan Kampung UKM Digital kedepan.

Strategic Situational Analityc

Pergeseran perilaku masyarakat Indonesia dalam menggunakan teknologi digital mendorong pertumbuhan e-commerce di Indonesia sebagaimana terlihat pada Gambar 3.

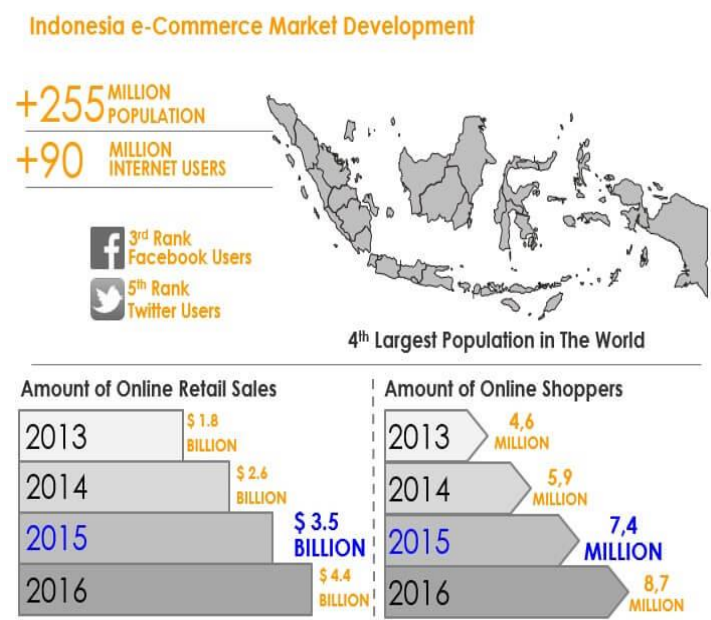

JURNAL

MANAJEMEN INDONESIA

Vol.16 - No.2

APRIL 2016

Gambar 2

ASEAN SME Index

Policy 2014
Gambar 3

e-Commerce Market

Development in

Indonesia

Sumber: Spire research 


\section{JURNAL}

MANAJEMEN

INDONESIA

\section{Vol.16 - No.2}

APRIL 2016
Dengan melihat populasi yang besar 259 juta, merupakan suatu peluang besar bagi UKM untuk memasarkan produknya, dari 326 juta pengguna mobile phone dan lebih dari 88 juta pengguna internet, serta lebih dari 79 juta pengguna facebook akan semakin membuka peluang dan memudahkan UKM dalam melakukan promosi dan mengembangkan usaha melalui media digital (Partner, 2016). Di Indonesia, rata-rata orang menghabiskan waktu untuk menggunakan internet adalah 4,42 jam/ hari (desktop) dan 3,33 jam/hari melalui mobile phone serta untuk menggunakan social media rata-rata $2,51 \mathrm{jam} / \mathrm{hari}$ dan menonton televisi 2,22 jam/hari (We Are Social, 2016), ini menandakan bahwa menggunakan internet dan social media sudah menjadi behaviour di Indonesia.

Pertumbuhan pengguna internet, mobile user, dan pengguna social media, mendorong pergeseran perilaku belanja konsumen digital Indonesia menuju online shopping. Tren penjualan malalui internet semakin naik, dengan demikian tampaknya, perilaku konsumen Indonesia mulai terbiasa dengan belanja online. Tren belanja online di Indonesia akan semakin cerah di masa mendatang.E-commerce, Advertising, dan Financial Services merupakan tiga pendorong utama pertumbuhan digital consumer di Indonesia. Market size consumer digital Indonesia tahun 2020 diperkirakan mencapai Rp 170 Trilyun. Barang elektronik termasuk gadget dan fashion merupakan produk online yang paling banyak dibeli oleh konsumen digital Indonesia, salah satu faktor yang menjadi pertimbangan utama bagi konsumen digital saat melakukan online shopping adalah faktor keamanan.
Gambar 4.

Indonesia Digital

Consumer Opportunity

(Sumber: Delta Partners,

8 Juni 2016)

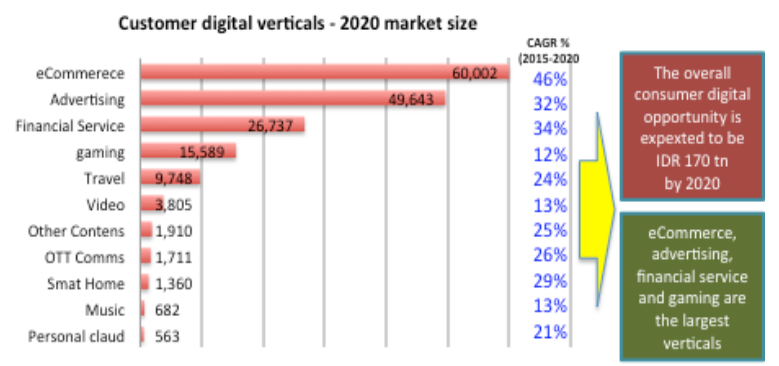

Biaya promosi secara tradisional (offline) lebih mahal dibandingkan biaya promosi yang harus dikeluarkan melalui media digital. Beberapa macam media promosi tradisional, yaitu print media (koran, majalah, brosur), broadcast media, direct mail, dan telemarketing. Sementara itu promosi secara digital dapat dilakukan melalui website, social networking, video marketing, dan digital advertising.

\section{Landasan Teori}

\subsection{Penentuan Strategi}

Strategi adalah alat untuk mencapai tujuan (Rangkuti, 2004). Strategi adalah tindakan yang bersifat incremental (senantiasa meningkat) dan terus menerus dan dilakukan berdasarkan sudut pandang tentang apa yang diharapkan oleh para pelangan di masa depan (Hamel dan Prahalad, 1995). Strategi (strategy) secara eksplisit, yaitu rencana tindakan yang menerangkan tentang alokasi sumber daya serta berbagai aktivitas untuk menghadapi lingkungan, memperoleh keunggulan bersaing, dan mencapai tujuan perusahaan (Daft, 2010). Keunggulan bersaing (competitive advantege) adalah hal yang membedakan suatu perusahaan dari perushaan lain dan memberi ciri khas bagi perusahaan untuk memenuhi kebutuhan pasar konsumen. Inti perumusan strategi adalah menentukan bagaimana perusahaan kita akan berbeda dengan perusahaan lain. Strategi tentu saja berubah seiring waktu sesuai dengan kondisi lingkungan, namun agar tetap kompetitif $m$ strategi perushaan yang berfokus kepada: Pemanfaatan kompetensi dasar, Mengembangkan sinergi, dan Menciptakan Nilai Bagi Pelanggan (Daft, 2010).

\subsection{Analisis SWOT}

Pengertian analisis SWOT Analisis SWOT (SWOT analysis) yakni mencakup upaya-upaya untuk mengenali kekuatan, kelemahan, peluang, dan ancaman yang menentukan kinerja perusahaan. Informasi eksternal mengeni peluang dan ancaman 
dapat diperoleh dari banyak sumber, termasuk pelanggan, dokumen pemerintah, pemasok, kalangan perbankan, rekan diperusahaan lain. Banyak perusahaan menggunakan jasa lembaga pemindaian untuk memperoleh keliping surat kabar, riset di internet, dan analisis tren-tren domestik dan global yang relevan (Daft, 2010). Analisis SWOT adalah identifikasi berbagai faktor secara sistematis untuk merumuskan strategi perusahaan (Rangkuti, 2004). Analisis ini didasarkan pada logika yang dapat memaksimalkan kekuatan (strength) dan peluang (opportunity), namun secara bersamaan dapat meminimalkan kelemahan (weakness) dan ancaman (threats). Proses pengambilan keputusan strategi selalu berkaitan dengan pengembangan misi, tujuan, strategi dan kebijakan perusahaan. Dengan demikian, perencanaan strategi harus menganalisa faktor-faktor strategi perusahaan (kekuatan, kelemahan, peluang dan ancaman) dalam kondisi yang saat ini.

Analisis SWOT membandingkan antara faktor eksternal peluang (opportunity) dan ancaman (threats) dengan faktor internal kekuatan (strenght) dan kelemahan (weakness). Untuk menganalisis secara lebih dalam tentang SWOT (Fahmi, 2013). Faktor eksternal mempengaruhi terbentuknya opportunities and threats $(\mathrm{O}$ dan $\mathrm{T})$. Dimana faktor ini menyangkut dengan kondisi-kondisi yang terjadi di luar perusahaan yang mempengaruhi dalam pembuatan keputusan perusahaan. Faktor ini mencakup lingkungan industri dan lingkungan bisnis makro, ekonomi, politik, hukum, teknologi, kependudukan, dan sosial budaya. Faktor internal ini mempengaruhi terbentuknya strenghts and weaknesses ( $\mathrm{S}$ dan W). Dimana faktor ini menyangkut dengan kondisi yang terjadi dalam perusahaan, yang mana ini turut mempengaruhi terbentuknya pembuatan keputusan (decision making) perusahaan. Faktor internal ini meliputi semua macam manajemen fungsional: pemasaran, keuangan, operasi, sumberdaya manusia, penelitian dan pengembangan, sistem informasi manajemen dan budaya perusahaan (corporate culture).

\subsection{Matrik SWOT}

Alat yang dipakai untuk menyusun faktor-faktor strategis perusahaan adalah matrik SWOT. Matrik ini dapat mengambarkan secara jelas bagaimana peluang dan ancaman eksternal yang dihadapi perusahaan dapat disesuaikan dengan kekuatan dan kelemahan yang dimilikinya. Matrik ini dapat menghasilkan 4 set kemungkinan alternatif strategis.

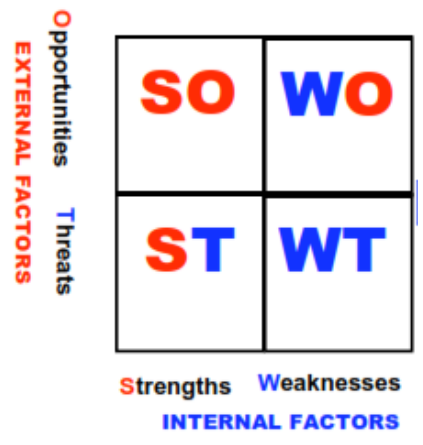

Strategi SO dibuat berdasarkan jalan pikiran perusahaan, yaitu dengan memanfaatkan seluruh kekuatan untuk merebut dan memanfaatkan peluang yang sebesar-besarnya. Strategi ST (Strenghts-Threats) adalah strategi dalam menggunakan kekuatan yang dimiliki perusahaan untuk mengatasi ancaman. Strategi WO (Weknesses-Opportunities) diterapkan berdasarkan pemanfaatan peluang yang ada dengan cara meminimalkan kelemahan yang ada. Strategi WT (Weknesses-Threats) berdasarkan pada kegiatan yang bersifat defensive dan berusaha meminimalkan kelemahan yang ada serta menghindari ancaman.

\subsection{Strategi Kompetitif}

Dalam bukunya (Rangkuti, 2004). Keberhasilan suatu strategi yang telah ditetapkan sangat ditentukan oleh seberapa besar tingkat kesesuaian strategi tersebut dengan perubahan lingkungan, pesaing, serta situasi organisasi faktor-faktor dalam merumuskan strategi meliputi: Dalam Kondisi Posisi Persaingan yang Kuat dan Membanggun Kekuatan Kompetitif. 


\subsection{Jenis Strategi Kompetitif}

Untuk mengetahui daya saingnya disetiap kekuatan, perusahaan mengunakan salah satu dari tiga strategi: diferensiasi, kepemimpinan biaya, atau fokus. Karkteristik perusahaan yang bisa dikaitkan dengan setiap strategi (Porter, 1998).

\subsection{Merumuskan Strategi Kompetitif}

Cara yang efektif untuk merumuskan strategi adalah lima kekuatan dan strategi kompetitif, sejumlah perusahaan dan menyatakan bahwa strategi tingkat-usaha merupakan hasil dari lima kekuatan kompetitif dilingkungan perusahaan (Porter, 1998).

Lima Kekuatan Kompetitif Porter Kekuatan - kekuatan kompetitif yang ada dilingkungan perusahaan dan menunjukan pengaruh teknologi internet terhadap setiap kekuatan. Kekuatan-kekuatan ini membantu menentukan posisi perusahaan versus pesaingnya di dunia industri yaitu: Potensi pesaing baru, Daya tawar pembeli, Daya tawar pemasok, Ancaman produk pengganti, dan Pesaing antarkompetitor.

\section{Metode Penelitian}

Gambar 6.

Research Framework

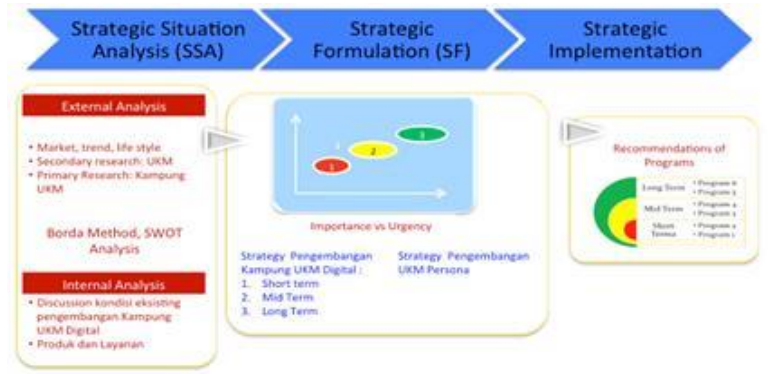

Objek penelitian ini adalah Program Kampung UKM Digital yaitu program pengembangan digitalisasi UKM dengan menyediakan konektivitas dan konten $e$ commerce di sentra-sentra UKM. Penelitian ini mengacu pada kerangka proses manajemen strategi hingga pada tahap implementasi yaitu (1) Audit Lingkungan (Eksternal dan Internal), (2) Formulasi Strategi Pengembangan Kampung UKM Digital dan UKM personal, dan (3) Implementasi strategi berupa rekomendasi program-program jangka pendek, menengah, dan panjang (Gambar 6). Audit lingkungan eksternal dilakukan melalui desk research, sedangkan audit internal dilakukan melalui survei terhadap Kampung UKM Digital.

Penelitian ini memanfaatkan hasil indepth interview terhadap UKM di beberapa kota yang bergerak dalam bidang: Makanan Ringan, Tas dan Sulaman, Ikan Hias, Kaos, Batik, Kerajinan dan Pariwisata serta hasil survey pada lokasi 2 kampung UKM digital yang telah diresmikan oleh PT. Telkom pada pertengahan tahun 2015 dikota di Bandung dan Cirebon dengan jumlah sampel 60 UKM digital dan 10 UKM offline dalam rangka mengumpulkan informasi audit lingkungan Internal. Survei dilakukan menggunakan wawancara terstruktur yang terdiri dari 19 pertanyaan yang mewakili lima indikator yaitu akses internet, marketing, kinerja, financial, dan products knowledge \& customer needs. Terkait dengan karakteristik penelitian ekspolatory, peneliti memilih pertanyaan dengan format open-ended untuk memperoleh wawasan yang mendalam terhadap permasalahan yang dihadapi UKM pada program Kampung UKM Digital. Jika terdapat hal yang relevan dilakukan pertanyaan-pertanyaan yang mengikuti untuk menyelidiki atau menggali informasiinformasi tambahan.

Setiap wawancara dilakukan dalam jangka waktu berkisar 45-60 menit. Wawancara dilakukan oleh 3 orang peneliti. Setiap peneliti membuat catatan wawancara untuk kemudian digabungkan menjadi satu dokumen untuk dianalisis. Tabel SWOT dibangun berdasarkan ide-ide utama yang berkaitan dengan akses internet; pemasaran; kinerja; keuangan; dan product knowldge dan kebutuhan konsumen.

Setelah itu, informasi SWOT digunakan untuk merancang rekomendasi strategi jangka pendek, menengah, dan panjang bagi pengembangan Kampung UKM Digital dan UKM Personal. Lebih lanjut, pada tahap implementasi strategi, rekomendasi-rekomendasi strategi tersebut dirinci kedalam program-program jangka pendek, menengah, dan panjang. 
Para UKM di Indonesia tingkat keterlibatan secara digital dapat dikategorikan/ dikelompokkan kedalam 4 kategori sebagai berikut:

1) Bisnis offline; yaitu bisnis yang tidak memiliki akses terhadap broadband, tidak memiliki komputer atau smartphone dan tidak memiliki website serta tidak memiliki kehadiran secara online.

2) Bisnis online dasar; yaitu bisnis yang memiliki akses broadband/ terhubung ke internet secara sederhana dan alat digital seperti komputer dan smartphone. Namun, bisnis tersebut tidak terlibat dalam media sosial (kecuali email) dan tidak memiliki kemampuan e-commerce untuk pemesanan atau pembayaran.

3) Bisnis online menengah; bisnis yang memiliki konektivitas digital dan juga secara aktif terlibat dalam media sosial atau dengan mengintegrasikan situs mereka dengan media sosial, live chat atau ulasan konsumen. Bisnis ini belum memiliki kapabilitas $e$ commerce sepenuhnya.

4) Bisnis online lanjutan; yaitu bisnis yang memiliki konektivitas, integrasi jejaring sosial dan kapabilitas e-commerce. Secara definitif, semua bisnis online lanjutan telah memiliki fasilitas pemesanan dan pembayaran secara online.

\section{Hasil dan Pembahasan}

Hasil indepth interview dengan beberapa UKM, diberbagai jenis usaha bahwa secara garis besar kesulitan dari para UKM dapat dikelompokan menjadi 3 bagian yaitu:

1) UKM mengalami kesulitan mengakses internet karena terbatasnya ketersediaan infrastruktrur ICT.

2) UKM mengalami kendala dalam proses produksi:

a. Kesulitan mendapatkan bahan baku karena hanya memiliki daftar supplier yang terbatas.

b. Kesulitan mendapatkan tenaga kerja yang terampil.

c. Kesulitan melakukan pengelolaan inventory.

3) UKM belum dapat menjangkau pasar yang lebih luas:

a. Promosi masih dilakukan secara offline sehingga biaya yang dikeluarkan sangat tinggi dan tidak tepat sasaran.

b. Informasi tentang produk UKM terbatas sehingga konsumen tidak mengetahui produk yang dijual UKM.

c. Belum memiliki komunitas sehingga sulit untuk mengembangkan usaha.

Disamping hasil desk research, survey dan wawancara dilapangan terhadap pelaku usaha (UKM) diperoleh voice of customer sebagai berikut:

Voice of Customer UKM Digital:

1) UKM memiliki keterbatasan pengetahuan tentang internet dan pemasaran online.

2) Untuk kelancaran dan pengembangan usahanya, para UKM meminta diberikan pelatihan dan pendampingan hingga mereka dapat secara mandiri menggunakan teknologi ICT, termasuk penyedian sarana dan prasarana. Hal ini dikarenakan keterbatasan knowledge dari para UKM.

3) Mayoritas UKM belum mendapatkan dana pinjaman sehingga harus menggunakan modal sendiri (80\%), sedangkan $20 \%$ telah mendapatkan tambahan modal pinjaman.

4) Awareness UKM terhadap produk e-commerce masih rendah $(31,67 \%)$

\section{Voice of customer UKM Offline:}

1) UKM masih menjalankan usahanya secara offline dengan membuka toko sebagai outlet penjualan dan menggunakan komunikasi melalui telepon dan SMS.

2) Selama ini menggunakan modal kerja sendiri karena kesulitan dalam mengajukan pinjaman ke bank yang mensyaratkan anggunan.

3) Berharap order pesanan dari pelanggan eksisting dan calon pelanggan lain yg mengetahuinya baik pada saat datang ke outlet/ toko maupun rekomendasi dari pelanggan lainnya termasuk juga order dari rekan sekerja.

4) Para UKM enggan untuk menggunakan media internet karena keterbatasan pengetahuan dan tidak/ belum memiliki sarana yang dibutuhkan baik komputer maupun smartphone.

5) Para UKM merasakan bahwa penjualan/ order pesanan sangat dipengaruhi oleh kondisi lingkungan/ musim seperti Pilkada/ tahun ajaran baru, persaingan dan maraknya penjualan online sehingga omzet penjualan mengalami naik turun.

JURNAL

MANAJEMEN INDONESIA

Vol.16 - No.2

APRIL 2016 
JURNAL

MANAJEMEN

INDONESIA

Vol.16 - No.2

APRIL 2016
Berdasarkan pemaparan faktor-faktor eksternal dan internal diatas, maka dapat diidentifikasi opportunities, threats, strengths, dan weaknesses sebagai berikut:

1) Opportunities:

a. Pertumbuhan pengguna internet, mobile user, dan pengguna social media, mendorong pergeseran perilaku belanja konsumen digital Indonesia menuju online shopping dan mendorong pertumbuhan e-commerce di Indonesia.

b. E-commerce, Advertising, dan Financial Services merupakan tiga pendorong utama pertumbuhan digital consumer di Indonesia dengan market size yang terus meningkat.

c. Biaya promosi secara tradisional (offline) lebih mahal dibandingkan biaya promosi yang harus dikeluarkan melalui media digital.

d. Pemerintah Indonesia telah memiliki berbagai kebijakan yang dapat membantu pengembangan UKM, khususnya dalam mendorong pertumbuhan Gross Domestic Poduct (GDP) dan peningkatan Ekspor.

e. Meski belum siap, pasar bebas ASEAN (MEA) merupakan peluang bagi UKM untuk memperluas pasar regional.

f. Hasil survei menunjukkan bahwa adopsi teknologi digital terbukti dapat meningkatkan kinerja UKM, antara lain pada penigkatan Akses ke pelanggan baru di Dalam Negeri, Peningkatan Penjualan dan Akses market baru di Luar Negeri.

2) Threats:

a. Keamanan bertransaksi merupakan salah satu hal yang menjadi pertimbangan utama bagi konsumen digital Indonesia saat melakukan online shopping.

b. Market e-commerce Indonesia diperebutkan oleh banyak pemain dan belum ada yang tampak dominan. Lazada, Tokopedia, dan Elevenia untuk sementara menguasai market share e-commerce Indonesia.

c. Terdapat tiga permasalahan utama UKM, yaitu keterbatasan infrastruktur, banyaknya kendala dalam proses produksi (kesulitan mendapatkan bahan baku, mendapatkan tenaga kerja, dan sistem inventori) dan aksesibilitas pasar yang masih kecil.

d. Hasil survei di Kampung UKM Digital menunjukkan bahwa:

e. UKM memiliki keterbatasan pengetahuan tentang internet dan pemasaran online, sedangkan tingkat awareness terhadap produk e-Commerce masih rendah $(31,67 \%)$.

f. Ketersediaan akses internet masih sangat terbatas.

g. Mayoritas UKM tidak memperoleh dana pinjaman sehingga sulit mengembangkan usahanya karena pemodalan terbatas.

3) Strengths:

a. Program Kampung UKM Digital dapat mendukung dan mendorong pertumbuhan adopsi UKM terhadap teknologi digital.

b. Telah banyak layanan e-commerce bagi UKM, antara lain Lazada.com, JarvisStore.com dan Blanja.com dimana beberapa e-commerce ini telah dilengkapi dengan layanan payment solution sehingga memudahkan UKM dalam melakukan transaksi.

c. Selain layanan e-commerce, ada juga solusi yang dapat mendukung UKM dalam mengembangkan bisnisnya. Solusi ini terdiri dari penyediaan infrastruktur ICT dan konsultasi bisnis bagi UKM (Starbox, Smartbisnis, MangoSTAR).

d. Telkom telah memiliki layanan bantuan modal melalui Smart Funding.

e. Telkom memiliki solusi untuk membantu proses produksi melalui Aplikasi Supply Chain Management.

4) Weaknesses:

a. Program Kampung UKM Digital belum berjalan maksimal sesuai dengan yang telah direncanakan, baik dalam penyediaan sarana dan prasarana maupun dalam kerjasama dengan pihak lain dalam konsep PentaHelix.

b. Program pelatihan dan pendampingan UKM belum berjalan secara baik meski telah disusun kurikulum pelatihan bagi UKM. 
c. Jumlah Akses Point Wifi.ID, sebagai alternatif pengganti yang terpasang di Kampung UKM Digital masih perlu diperbanyak.

Sehingga dapat dipetakan strategi dari masing-masing sebagaimana terlihat pada Gambar-7

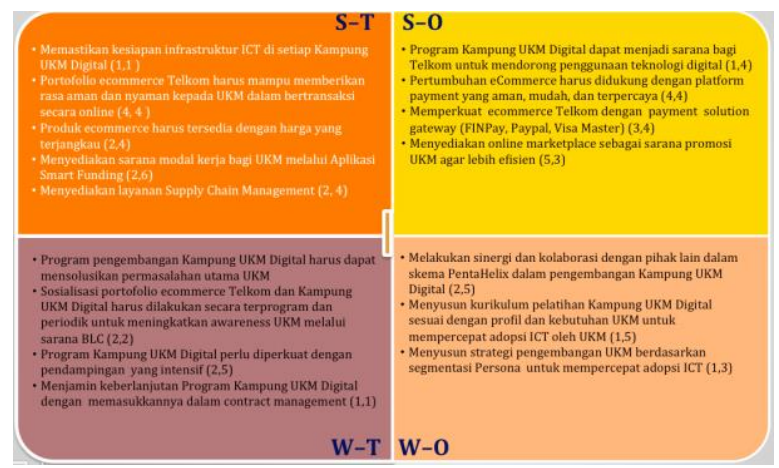

Agar strategi yang akan disusun mudah untuk diimplementasikan maka dihubungkan dengan tingkat kepentingan dan urgentcy nya sebagaimana terlihat pada Gambar 8.

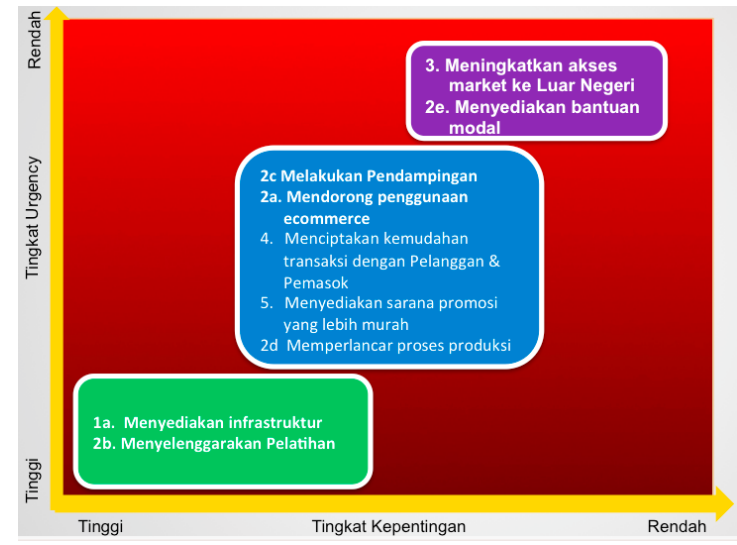

Sehingga strategi yang dapat disusun dalam pengembangan Kampung UKM Digital dan UKM Personal adalah sebagai berikut:

1) Jangka Pendek (dalam kurun waktu $<6$ bulan)

a. Menyediakan infrastruktur berupa pemasangan/ penambahan Akses Point Wifi.ID, menyiapkan jaringan 3G/4G dan menyiapkan layanan MangoSTAR (satelite) sebagai solusi akses internet bagi Kampung UKM yang berada di wilayah yang belum terjangkau layanan kabel, fiber maupun mobile.

b. Menyelenggarakan Pelatihan selain materi teknis tentang ICT dan Produk ecommerce juga materi tentang wawasan bisnis untuk menumbuhkan jiwa enterpreneurship dimana kurikulum disesuaikan dengan tingkat UKM dalam adopsi $I C T$

2) Jangka Menengah ( 6 bulan -1 tahun)

a. Mendorong penggunaan ecommerce antara lain dengan menyediakan layanan managed service operational ecommerce bagi UKM yang tidak mampu mengelola bisnis onlinenya sendiri.

b. Melakukan pendampingan oleh tenaga Wira IT untuk memastikan UKM dapat mengimplementasikan $e$-commerce sendiri.

c. Menciptakan kemudahan transaksi bagi pelanggan \& pemasok dengan mempercepat implementasi solusi Supply Chain Management (SCM) yang dilengkapi dengan solusi pembayaran yang lengkap serta terintegrasi dengan layanan jasa pengiriman barang offline maupun online.

d. Menyediakan sarana promosi yang lebih murah yang terintegrasi dengan media sosial.
JURNAL

MANAJEMEN INDONESIA

Vol.16 - No.2

APRIL 2016

Gambar 7

SWOT Strategic Analysis

Gambar 8 .

Strategi Pengembangan Kampung UKM Digital 
JURNAL

MANAJEMEN

INDONESIA

Vol.16 - No.2

APRIL 2016

Gambar 9.

Review Road Map

Kampung UKM Digital

Gambar 10.

Program Penta Helix e. Mendukung kelancaran proses produksi dengan mengembangkan marketplace pemasok untuk mempermudah UKM dalam mendapatkan bahan baku, mendorong menggunakan aplikasi online rekrutmen tenaga kerja dan memanfaatkan layanan inventory management system.

3) Jangka Panjang (di atas 1 tahun)

a. Meningkatkan akses market ke Luar Negeri, bekerjasama dengan pemerintah dalam menciptakan regulasi yang memudahkan UKM dalam melakukan export produknya, memfasilitasi UKM yang memiliki produk berkualitas dan peluang pasar di luar negeri dalam penyelenggaraan event/ pameran internasional dengan menyediakan boot bagi UKM dan meningkatkan Search Engine Optimization(SEO) bagi produk-produk di marketplace/ toko online agar selalu berada di peringkat atas dalam mesin pencari.

b. Menyediakan bantuan modal kerja dengan mempercepat implementasi Smart Funding dan melakukan pembinaan kepada para UKM.

4) Selain hal diatas diperlukan strategi pengembangan UKM Personal sesuai dengan tingkat keterlibatan secara digital sbb:

a. Bisnis offline; memberikan edukasi dan menyediakan connectivity.

b. Bisnis online dasar; memberikan edukasi dan pendampingan tentang online marketing dan e-commerce.

c. Bisnis online menengah; menyediakan broadband access internet dan content

d. Bisnis online lanjutan; menyediakan broadband access internet dengan service level guarante, content dan data analitik.

Beberapa program yang diperlukan untuk mendukung keberhasilan Kampung UKM Digital adalah sebagai berikut:

1) Review Road Map Kampung UKM Digital; diperlukan beberapa perbaikan terutama dalam penyediaan infrastruktur dan pelaksanaan pelatihan sebagaimana terlihat pada Gambar-9

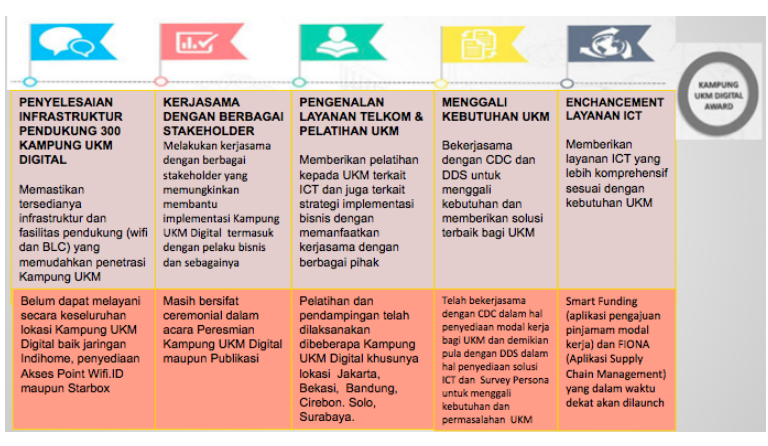

2) Melakukan kerjasama dengan beberapa institusi (program Penta Helix "ABCGM") agar dapat secara cepat membuahkan hasil yang diharapakan yaitu dengan Akademi, Pelaku Bisnis, Community, Goverment dan Media seperti terlihat pada Gambar-10

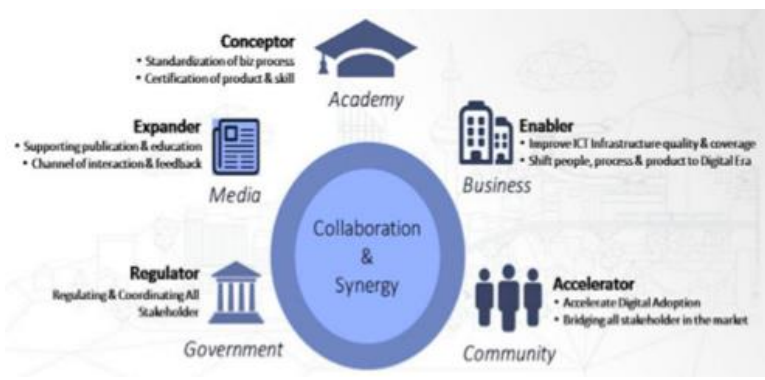


3) Dukungan terhadap sarana yang diperlukan untuk kelancaran dalam pelaksanaan berupa Penyediaan Wifi Corner, Broadband Learning Access, Penyediaan Layanan ICT, Pelatihan dan pendampingan serta Bantuan Modal Usaha sebagaimana terlihat pada Gambar-11.

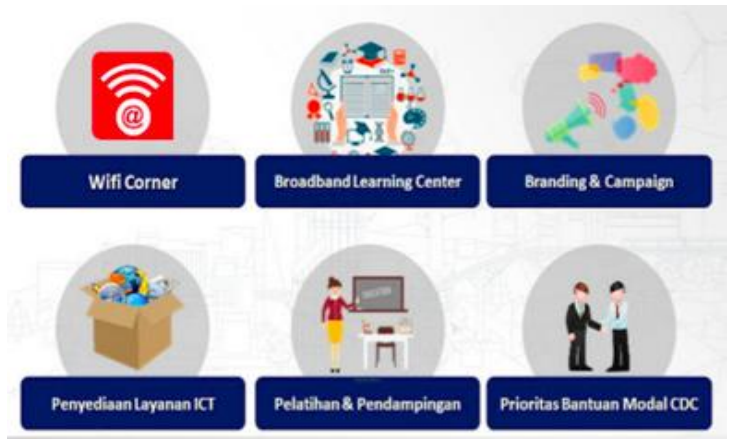

JURNAL

MANAJEMEN INDONESIA

Vol.16 - No.2

APRIL 2016

Gambar 11.

Sarana Kampung UKM

Digital

4) Kurikulum pelatihan agar para UKM dapat menjankan usahanya dengan maksimal dan dapat berjalan dengan lancar maka perlu diberikan pelatihan yang disesuaikan dengan tingkatannya terbagi dalam Basic, Intermediate dan Advance

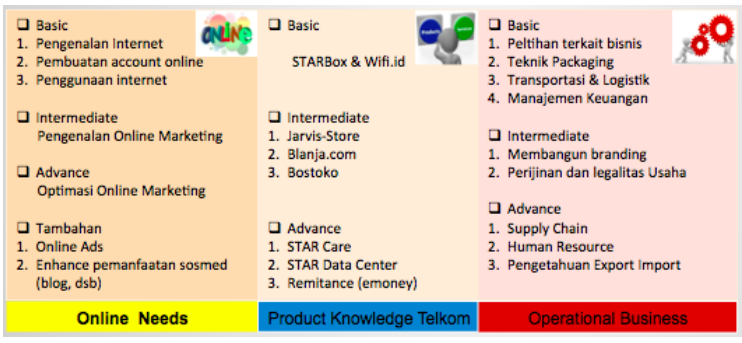

Gambar 12

Kurikulum

Pelatihan

\section{5) Kesimpulan dan Saran}

\subsection{Kesimpulan}

Bahwa adopsi teknologi digital terbukti dapat meningkatkan kinerja UKM, terutama pada Peningkatan Akses ke pelanggan baru di Dalam Negeri dan Peningkatan Penjualan.

Kesulitan para UKM dalam mengakses internet karena terbatasnya ketersediaan infrastruktur ICT, dapat disolusikan dengan memperbanyak Akses Point (AP) Wifi.ID di setiap Kampung UKM Digital, menyiapkan jaringan 3G/4G sebagai alternatif akses broadband internet bagi UKM yang membutuhkan akses internet cepat, dan menyiapkan layanan MangoSTAR sebagai solusi akses internet bagi Kampung UKM yang berada di wilayah yang belum terjangkau layanan kabel, fiber maupun mobile.

Kesulitan para UKM yang berkaitan dengan proses produksi dapat tersolusi dengan mempercepat implementasi solusi Supply Chain Management (SCM) yang dapat memberikan kemudahan bagi UKM dalam mendapatkan bahan baku dari pemasok, mendorong UKM untuk menggunakan aplikasi online rekrutmen tenaga kerja, dan menyediakan management inventory system untuk mempermudah pengelolaan barang.

Kesulitan UKM dalam memperluas jangkauan pasar dapat tersolusikan dengan mendorong UKM untuk mengadopsi teknologi digital melalui penyediaan solusi managed service operational layanan ecommerce dan mempercepat pengembangan advertising agar UKM memperoleh sarana promosi melalui sosial media marketing yang efektif dan efisien.

\subsection{Saran}

Agar Program dan Strategi Pengembangan Kampung UKM Digital dapat berjalan sebagaimana yang diharapkan maka diperlukan kesungguhan dari berbagai pihak baik dilingkungan internal Telkom sebagai salah satu penyedia jaringan akses internet, content, Pemerintah sebagai pemangku kebijakan yang antara lain dalam hal perijinan, kemudahan export produk UKM maupun Akademisi dalam implementasinya. 


\section{Daftar Pustaka}

Asean SME Policy Index. 2014. Asean SME Policy Index [Online]. Tersedia pada : http://www.eria.org/Key_Report_FY2012_No.8_prologue.pdf [31 Agustus 2016]

JURNAL

MANAJEMEN

\section{INDONESIA}

\section{Vol.16 - No.2}

APRIL 2016
Delloite. 2015. UKM Pemicu kemajuan Indonesia: Instrumen pertumbuhan bangsa [Online]

Tersedia pada: http://www2.deloitte.com/content/dam/Deloitte/id/Documents/finance/id-fas-smepowering-indonesia-success-report-bahasa-noexp.pdf [31 Agustus 2016]

eJournal Ilmu Hubungan Internasional. 2013. Persiapan Indonesia Dalam Menghadapi MEA (Masyarakat Ekonomi ASEAN) [Online]. Tersedia pada : ejournal.hi.fisipunmul.ac.id/ [31 Agustus 2016]

Freddy Rangkuti. 2005. Analisis SWOT : Teknik Membedah Kasus Bisnis. Jakarta: PT. Gramedia Pustaka Utama

Hamel, G dan Prahalad, C, K, 1995. Kompetisi Masa Depan. Jakarta : PT.Bina Rupa Aksara.

Irham Fahmi. 2013. Manajemen Strategis Teori dan Aplikasi. Bandung: PT.ALFABET

merdeka.com. 2014. Jumlah UMKM Indonesia 57,9 juta, terbanyak dibanding negara lain [Online]. Tersedia pada: http://www.merdeka.com/uang/jumlah-umkm-indonesia-579juta-terbanyak-dibanding-negara-lain.html [13 September 2016]

Partner, D. 2016. Indonesia Digital Consumer Opportunity [Online]. Tersedia pada : https://cdn-ds.kilatstorage.com/wp-content/uploads/2016/08/wearesocial-1.png [31 Agustus 2016]

Rustono. 2013. Pemanfaatan Teknologi Informasi Dan Pengaruhnya Terhadap Kinerja Usaha Kelompok Bisnis Entrepreneur [Online]. Tersedia pada : http://admisibisnis.blogspot.com/2013/12/pemanfaatan-teknologi-informasi-dan.html

Richard L Daft. 2010. Era Baru Manajemen. Jakarta: PT.Salemba Empat

Michale E Porter. 1998. Competitive Strategy : Techniques for Analyzing Industries and Competitors. New York : Free Press

We Are Social. 2016. Penggunaan Internet di indonesia [Online]. Tersedia pada : http://wearesocial.com/uk/special-reports/digital-in-2016 [31 Agustus 2016] 